\title{
Chronic stress induces ageing-associated degeneration in rat Leydig cells
}

\author{
Fei-Fei Wang, Qian Wang, Yong Chen, Qiang Lin, Hui-Bao Gao and Ping Zhang
}

Several studies have suggested that stress and ageing exert inhibitory effects on rat Leydig cells. In a pattern similar to the normal process of Leydig cell ageing, stress-mediated increases in glucocorticoid levels inhibit steroidogenic enzyme expression that then results in decreased testosterone secretion. We hypothesized that chronic stress accelerates the degenerative changes associated with ageing in Leydig cells. To test this hypothesis, we established a model of chronic stress to evaluate stress-induced morphological and functional alterations in Brown Norway rat Leydig cells; additionally, intracellular lipofuscin levels, reactive oxygen species (ROS) levels and DNA damage were assessed. The results showed that chronic stress accelerated ageing-related changes: ultrastructural alterations associated with ageing, cellular lipofuscin accumulation, increased ROS levels and more extensive DNA damage were observed. Additionally, testosterone levels were decreased. This study sheds new light on the idea that chronic stress contributes to the degenerative changes associated with ageing in rat Leydig cells in vivo.

Asian Journal of Andrology (2012) 14, 643-648; doi:10.1038/aja.2011.183; published online 21 May 2012

Keywords: Ageing; chronic stress; DNA damage; Leydig cells; reactive oxygen species

\section{INTRODUCTION}

Stress, both psychological and physiological, is common, and the study of stress is attracting increasing attention. Although the relationship between stress and ageing has been known for a long time, the theory of stress-induced ageing was first proposed in the $1950 \mathrm{~s} ;^{1}$ subsequently, the glucocorticoid hypothesis of brain ageing was proposed in the late $1970 \mathrm{~s}^{2}$ and then studied in depth. ${ }^{3,4}$ These investigation led to the more general proposal that stress accelerates the ageing process in other tissues and organs of the body, including the male reproductive system. The ability of stress to interfere with reproductive function has long been recognized ${ }^{5}$ and is characterized by reduced serum testosterone levels. ${ }^{6-8}$ Located in the male testes, Leydig cells are the primary source of the steroid hormone testosterone. Similar to the process of Leydig cell ageing, stress inhibits steroidogenic enzyme expression, subsequently decreasing testosterone secretion. ${ }^{6,7,9}$

Lipofuscin is an undegradable polymorphous waste material that accumulates in the lysosomal compartment of post-mitotic and slowly dividing cells; importantly, lipofuscin levels progressively increase with age. For this reason, the change in the amount of lipofuscin within the senescenct cells is considered as a marker of cellular ageing. ${ }^{10}$ Oxidative stress induced by reactive oxygen species (ROS) is a crucial trigger of lipofuscin formation. ${ }^{11}$ Known as free oxygen radicals, ROS are continuously produced in Leydig cells as in other cells during normal cellular aerobic metabolism via the mitochondrial electron transport chain. Additionally, ROS are synthesized as a by-product of steroidogenesis, especially during steroid hydroxylation by cytochrome P450 enzymes. In various ageing systems, steady-state ROS levels have been observed to increase with age. ${ }^{12}$ Consistent with these findings, similar results have been observed in aged Leydig cells. ${ }^{13}$ Although the causes of cellular dysfunction of Leydig cells during ageing are still unknown, oxidative stress is implicated ${ }^{14}$ and the free radical theory of ageing has been generally accepted. ${ }^{12}$ Additionally, damaged DNA can also be detected in senescent cells. ${ }^{15-17}$ DNA is particularly susceptible to be damaged by ROS or other stresses, such as ionizing radiation and ultraviolet light; if effective repair mechanisms fail or are absent, the accumulation of DNA damage can trigger genomic instability and cellular senescence. ${ }^{18}$

To confirm the hypothesis that chronic stress may accelerate the ageing process in Leydig cells and to examine the mechanisms underlying stress-induced ageing in Leydig cells, adult male Brown Norway (BN) rats were subjected to chronic unpredictable stress. Rat Leydig cells were then assessed for morphological alterations and lipofuscin accumulation. To investigate a possible mechanism, we also examined ROS levels and DNA damage levels. This study is the first to investigate whether chronic stress can accelerate the degenerative changes associated with Leydig cell ageing; importantly, the possible mechanisms underlying the stress-induced changes were also examined.

\section{MATERIALS AND METHODS}

Animals and stress model

Male BN rats aged 6 and 21 months were purchased from the Animal Center of the Chinese Academy of Sciences (Shanghai, China). The rats were raised in a controlled environment $\left(22+2{ }^{\circ} \mathrm{C} ; 12 \mathrm{~h} \mathrm{light/dark}\right.$ cycle, lights on at 9 a.m.); food and water were provided ad libitum. All animal procedures (protocol number 03-048, renewed 25 September 
2003) were approved by the Institutional Animal Care and Use Committee of School of Medicine Shanghai Jiao Tong University.

Rats were divided into the following groups consisting of ten animals each: (i) young control group, freely moving 6-month-old BN rats; (ii) chronic stress group, 6-month-old $\mathrm{BN}$ rats were subjected to chronic unpredictable stress for 40 consecutive days; (iii) old group, 21-monthold $\mathrm{BN}$ rats. The rats in the stress group were subjected to the random stressor at 9:00 a.m. each day. The control and old rats were sampled at the same time-points, but they were undisturbed for the duration of the experiment. For 40 consecutive days, rats in the chronic stress group were exposed to one of the following stressors each day: immobilisation, forced swimming in ice-cold water, crowding without food or water and being kept in a room at $4{ }^{\circ} \mathrm{C}$. Immobilisation: rats were restrained in wire mesh restrainers $(19 \mathrm{~cm}$ circumference $\times 40 \mathrm{~cm}$ long) for $3 \mathrm{~h}$. Swimming in ice-cold water: rats were forced to swim in ice-cold water for $5 \mathrm{~min}$. Crowding without food or water: 10 rats were placed into a small cage to simulate crowding; no food or water was given for $24 \mathrm{~h}$. Kept at $4{ }^{\circ} \mathrm{C}$ : rats were kept in a cold room at $4{ }^{\circ} \mathrm{C}$ for 20 min daily. The chronic unpredictable stress sequence consisted of different types of stressors presented randomly, once a day, over a period of 40 days. At the end of each stress period, the animals were asphyxiated using $\mathrm{CO}_{2}$. After decapitation, trunk blood was collected immediately and centrifuged at $500 \mathrm{~g}$. The serum supernatants were stored at $-80{ }^{\circ} \mathrm{C}$. Testes were retained. The overall design was repeated three times.

\section{Determination of serum hormone levels}

Corticosterone (glucocorticoid in rats) assay. Corticosterone concentrations were determined using a Corticosterone EIA Kit ${ }^{19}$ (Cayman Chemical, Ann Arbor, MI, USA); all analyses were performed according to the manufacturer's instructions. Antibody cross-reactivity to other steroids did not exceed $1.01 \%$. The assay specificity was $100 \%$ for Corticosterone and the assay sensitivity was $230 \mathrm{pg} \mathrm{ml}^{-1}$ (detection limit: $40 \mathrm{pg} \mathrm{ml}^{-1}$ ); the intra-assay coefficient was $9.0 \%$. Absorbance at $412 \mathrm{~nm}$ was measured using a PowerWaveX Microplate Spectrophotometer (BioTek, Winooski, VT, USA).

Testosterone assay. Serum testosterone concentrations were determined using a Testosterone EIA Kit ${ }^{19}$ (Cayman Chemical) based on the competition between testosterone and a testosterone-acetylcholinesterase $(\mathrm{ACHe})$ conjugate for a limited number of testosterone-specific binding sites. Testosterone standards were prepared according to the manufacturer's instructions. Serum samples were diluted 1:10 and processed in duplicate. Following the preparation of testosterone standards, the standards, the serum samples and the necessary controls were loaded into 96-well plates. Each well was coated with mouse anti-rabbit IgG. Testosterone-specific ACHe tracer was added to the appropriate wells; next, rabbit anti-testosterone antiserum was added to the appropriate wells. The plates were then incubated for $1 \mathrm{~h}$ at room temperature to allow for competitive binding. After plates were washed, the concentration of testosterone was determined by measuring the enzymatic activity of ACHe with Ellman's reagent, which contains the substrate for ACHe. The product of this enzymatic reaction has a yellow colour that absorbs at $412 \mathrm{~nm}$. The plates were left to develop in the dark for approximately $1 \mathrm{~h}$ before being read at $412 \mathrm{~nm}$ using a PowerWaveX Microplate Spectrophotometer (BioTek). All samples for hormone measurement were quantified in the same assay. The assay specificity for testosterone was $100 \%$ and the intra-assay coefficient was $9.0 \%$; the detection limit was $6 \mathrm{pg} \mathrm{ml}^{-1}$. The results were calculated with a computer spreadsheet program provided by Cayman Chemicals (http:// www.caymanchem.com/eiatools/promo/kit).

\section{Stereological analyses of Leydig cell numbers}

Rats were anaesthetized using $\mathrm{CO}_{2}$ and sedated with $0.3 \%$ pentobarbital sodium; next, they were perfused with $2 \%$ (v/v) glutaraldehyde via the abdominal aorta. After perfusion, the testes were removed. Sampling for stereology was performed according to the fractionator technique. ${ }^{20,21}$ In brief, the testes were sliced into discs, of which every fifth (fraction $f 1=1 / 5$ ) was collected; the discs were then sliced into slabs, of which every twelfth $(f 2=1 / 12)$ was collected. Finally, the slabs were sliced into blocks, of which every fiftieth $(f 3=1 / 50)$ was collected. Blocks were then embedded in Epon resin. Pairs of 5- $\mu \mathrm{m}$ sections were cut, and every sixtieth $(f 4=1 / 60)$ pair was collected and mounted on glass slides until the block was sectioned exhaustively. The sections were stained with haematoxylin-eosin and examined using light microscopy (Nikon, Michigan City, IN, USA). Images of every sixtieth $(f 5=1 / 60)$ field scanned on the tissue sections were analysed using ImagePro software (Media Cybernetics, Silver Spring, MD, USA). The counting frame, which was imposed electronically, represented an area of approximately $5500 \mu^{2}$ on the tissue section. The total number of Leydig cells per testis was calculated by multiplying the average number of Leydig cells counted in the test volume $\left(5500 \mu \mathrm{m}^{2} \times 5 \mu \mathrm{m}=27500 \mu \mathrm{m}^{3}\right)$ by the inverse of the sampling probability. The sampling probability varied depending on the size of the testis, ranging from $1 \times 10^{-7}(1 / f 1 \times f 2 \times f 3 \times f 4 \times f 5)$ in atrophied testes from aged rats to $22 \times 10^{-7}$ in larger testes from young and aged animals.

\section{Electron microscope analysis}

Rats were anaesthetized using $\mathrm{CO}_{2}$ and injected i.p. with $0.3 \%$ pentobarbital sodium; next, they were perfused with $2 \%(\mathrm{v} / \mathrm{v})$ glutaraldehyde via the abdominal aorta. After perfusion, the testes were removed. Small fragments approximately $1.5 \mathrm{~mm}$ wide were taken from different sites of each testis and immersed in $2 \%(\mathrm{v} / \mathrm{v})$ glutaraldehyde in phosphate-buffered saline (PBS, pH 7.4) for $2 \mathrm{~h}$ at $4{ }^{\circ} \mathrm{C}$. After being washed with PBS, the fragments were post-fixed in $1 \%$ $(\mathrm{w} / \mathrm{v})$ osmium tetroxide in PBS ( $\mathrm{pH}$ 7.4) for $2 \mathrm{~h}$ at $4{ }^{\circ} \mathrm{C}$. The fragments were then washed with PBS again, dehydrated and embedded in Epon following standard protocols. For each testis, an Epon-embedded specimen was taken at random and serial sections approximately $100 \mathrm{~nm}$ thick were cut. One of every four sections was mounted on a singlehole, formvar film-covered grid. The sections were double stained with saturated $3 \%(\mathrm{w} / \mathrm{v})$ uranyl acetate in $50 \%(\mathrm{v} / \mathrm{v})$ alcohol and lead citrate; slides were then observed using a transmission electron microscope (Philips CM120, Eindhoven, The Netherlands). ${ }^{22}$

\section{Isolation and purification of Leydig cells}

Rats were anaesthetized using $\mathrm{CO}_{2}$ and sacrificed by decapitation, and the testes were removed. The procedure for Leydig cell isolation was previously described. ${ }^{23}$ Briefly, the decapsulated testes were subjected to collagenase digestion in a $50 \mathrm{ml}$ plastic tube containing $10 \mathrm{ml}$ medium with collagenase (600 units) and DNase (750 units). The tubes were placed in a $34{ }^{\circ} \mathrm{C}$ water bath with constant agitation (50 times per min) for 15-20 min until the seminiferous tubules were separated. The enzyme activity was terminated by adding excess M199. Seminiferous tubules were removed by filtration through a $100-\mu \mathrm{m}$ pore size nylon mesh. The filtrates were centrifuged at $250 \mathrm{~g}$ for $10 \mathrm{~min}$ at $25^{\circ} \mathrm{C}$, which yielded crude interstitial pellets. These pellets were then suspended in $35 \mathrm{ml}$ of 55\% isotonic Percoll with 750 units DNase in Oakridge tubes. The tubes were centrifuged at $20000 \mathrm{~g}$ for $1 \mathrm{~h}$ at $4{ }^{\circ} \mathrm{C}$. Percoll fractions corresponding to densities of $1.070-1.090 \mathrm{~g} \mathrm{ml}^{-1}$ were collected. The cells present in the collected 
fractions were pelleted by centrifugation at $250 \mathrm{~g}$ for $10 \mathrm{~min}$ at $25{ }^{\circ} \mathrm{C}$ after being diluted with 3-4 volumes of medium. The purities of the isolated cell fractions were evaluated using histochemical staining for $3 \beta$-hydroxysteroid dehydrogenase activity using $0.4 \mathrm{nmol} 1^{-1}$ etiocholanolone as the steroid substrate. ${ }^{19,24}$ The mean purity of Leydig cells was $85 \%$.

\section{Senescence assays}

Intracellular lipofuscin was detected using autofluorescence. Following isolation, rat Leydig cells were washed twice in PBS. Autofluorescence was then analysed in a flow cytometer (BD Pharmingen, San Diego, CA, USA) with a 488-nm excitation and a 661-nm emission filter.

\section{Detection of intracellular ROS}

Intracellular ROS was detected using an oxidation-sensitive fluorescent probe (DCFH-DA). Following isolation, rat Leydig cells were washed twice in PBS. Cells were then incubated with $10 \mu \mathrm{mol} 1^{-1}$ DCFH-DA $\left(2^{\prime}, 7^{\prime}\right.$-dichlorofluorescin diacetate) at $37^{\circ} \mathrm{C}$ for $20 \mathrm{~min}$. DCFH-DA was deacetylated intracellularly by a nonspecific esterase, which was then further oxidized by ROS to the fluorescent compound 2,7-dichlorofluorescein (DCF). DCF fluorescence was detected using a flow cytometer (BD Pharmingen). For each sample, 10000 events were collected. ${ }^{25}$

\section{Measurement of DNA damage}

Genomic DNA damage was measured using a single cell gel electrophoresis assay (comet assay). Briefly, rat Leydig cells from each of the three groups were embedded in $0.6 \%(\mathrm{w} / \mathrm{v})$ low melting point agarose and then lysed in $2.5 \mathrm{moll}^{-1} \mathrm{NaCl}, 100 \mathrm{mmoll}^{-1}$ EDTA, $10 \mathrm{mmoll}^{-1}$ Tris- $\mathrm{HCl}(\mathrm{pH} 10), 1 \%(\mathrm{v} / \mathrm{v})$ Triton $\mathrm{X}-100$ at $4{ }^{\circ} \mathrm{C}$ overnight. Denaturation $(20 \mathrm{~min})$ followed by electrophoresis $(20 \mathrm{~min}$ at $25 \mathrm{~V}$ and $300 \mathrm{~mA}$ ) was performed in a solution of $0.3 \mathrm{~mol} \mathrm{l}^{-1} \mathrm{NaOH}$, $1 \mathrm{mmol} \mathrm{l}^{-1}$ EDTA $(\mathrm{pH}>13)$. Slides were then washed, stained with SYBR Green (Molecular Probes, Eugene, OR, USA) and observed using a fluorescent microscope. Slides were analysed using the Komet 5 analysis software (Kinetic Imaging, Liverpool, UK).

\section{Statistical analysis}

Each experiment was performed independently at least three times with similar results. Data are presented as the mean \pm s.e.m. Error bars indicate the standard deviation. The two-tailed Student's $t$-test was employed to evaluate the differences between groups. A $P<0.05$ was considered statistically significant.

\section{RESULTS}

\section{Serum glucocorticoid and testosterone concentrations}

An overabundance of glucocorticoid is the hallmark of stress. ${ }^{26}$ To verify our chronic stress model, we tested the serum corticosterone (glucocorticoid in rodents) concentrations. As shown in Figure 1, exposure to chronic stress for 40 days induced a significant increase in serum corticosterone levels in the chronic stress group compared with the control group (123.9 $\pm 10.5 \mathrm{ng} \mathrm{ml}^{-1}$ vs. $\left.49.2 \pm 7.2 \mathrm{ng} \mathrm{ml}^{-1}\right)(P<0.05)$; additionally, a significant reduction in serum testosterone levels was observed in the stress group compared with the young control group $\left(1.95 \pm 0.53 \mathrm{ng} \mathrm{ml}^{-1}\right.$ vs. $\left.3.97 \pm 0.76 \mathrm{ng} \mathrm{ml}^{-1}\right)(P<0.05)$. Together, these findings indicate that the stress model was successfully established. Circulating testosterone levels in old rats (21-month-old) were significantly decreased compared with the young control group $\left(1.48 \pm 0.07 \mathrm{ng} \mathrm{ml}^{-1}\right)(P<0.05)$; however, this decrease was not accompanied by altered serum glucocorticoid levels.
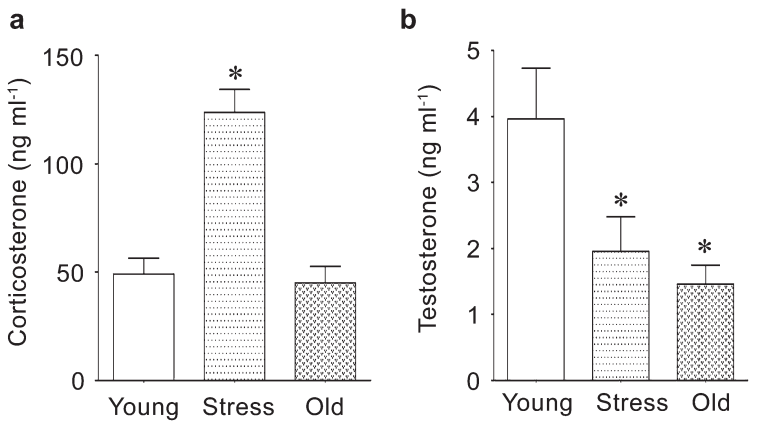

Figure 1 Serum glucocorticoid (a) and testosterone (b) concentrations of young control (6-month-old), chronically stressed and old (21-month-old) Brown Norway rats. The serum corticosterone levels of the stress group were increased significantly compared with the young control group (a); serum testosterone levels in both the stress and the old group were decreased significantly compared with the young control group (b). The results represent the mean \pm s.e.m. $* P<0.05$ compared with the Young group.

Effects of chronic stress on testis weight and Leydig cell numbers One or both testes of aged (21-month-old) rats were typically reduced in weight compared with those of the young rats (Figure 2a). Although all testes from young rats weighed at least $1.5 \mathrm{~g}$, only approximately half of the testes in the aged rats weighed $1.5 \mathrm{~g}$; the majority of the remaining testes in old rats weighed less than $1.0 \mathrm{~g}$. Importantly, following exposure to chronic stress, the weights of one or both testes decreased significantly $(P<0.05)$.

Testosterone production and testis weights were significantly reduced in rats exposed to 40 days of chronic stress compared with the young control rats (6-month-old) (Figures $\mathbf{1 b}$ and 2a). Circulating testosterone levels are determined by the steroidogenic capacities of individual Leydig cells and the total numbers of Leydig cells per testis. To examine whether the reduced testosterone production resulted from decreased numbers of Leydig cells in the chronically stressed rats, stereological methods at the light microscopic level were used to determine Leydig cell numbers (Supplementary Figure 1). As shown in Figure $\mathbf{2 b}$, there were no significant differences of the number of Leydig cells in the three groups. Taken together, these results indicate that reduced steroidogenic capability must result from the decreased ability of individual Leydig cell to produce testosterone.
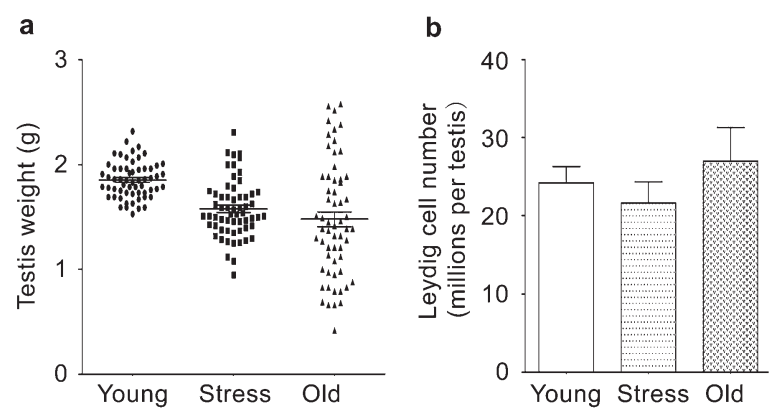

Figure 2 Testis weights (a) and Leydig cell numbers (b) in rats from the young (6month-old), chronically stressed and old (21-month-old) groups. Testis weight in rats in the stress group and the old group was decreased significantly compared with testis weights in rats from the young control group $(P<0.05)(\mathbf{a})$. There were no significant differences in Leydig cell numbers among the three groups (b). 
Effects of chronic stress on Leydig cell ultrastructure

Ultrastructural analysis showed that the chromatin in Leydig cells from chronically stressed rats was highly condensed and that the rim of heterochromatin beneath the nuclear membrane was not orbicular (Figure $3 \mathrm{c}$ and $\mathbf{d}$ ) compared with the young control cells (Figure 3a and b). The cytoplasmic organelles also presented senescence-associated degenerative changes, including dilation of the endoplasmic reticulum, mitochondrial swelling and large lipid droplets; these changes were also observed in the Leydig cells from aged rats (Figure $3 \mathbf{e}$ and $\mathbf{f}$ ). Additionally, lipofuscin deposition was marked in Leydig cells from chronically stressed rats (Figure 3c). Therefore, these results demonstrated that chronic stress could induce age-associated ultrastructral changes in Leydig cells.

Chronic stress promotes lipofuscin deposition in Leydig cells Senescent cells are characterized by increased levels of lipofuscin due to the cellular accumulation of the autofluorescent pigment. ${ }^{27}$ Leydig cells isolated from chronically stressed rats displayed a prominent increase in cellular autofluorescence compared with control cells, approximately six-fold after 40 days of chronic stress. Leydig cells isolated from old rats exhibited an average $>10$-fold increase in autofluorescence compared to young control rats, which reflects the nature of senescence (Figure 4). After 40 days of chronic stress, Leydig cells exhibited a narrow autofluorescence distribution, indicating uniform and synchronous entry into senescence. Taken together, these results indicated that chronic stress accelerated Leydig cells into a premature state of senescence.
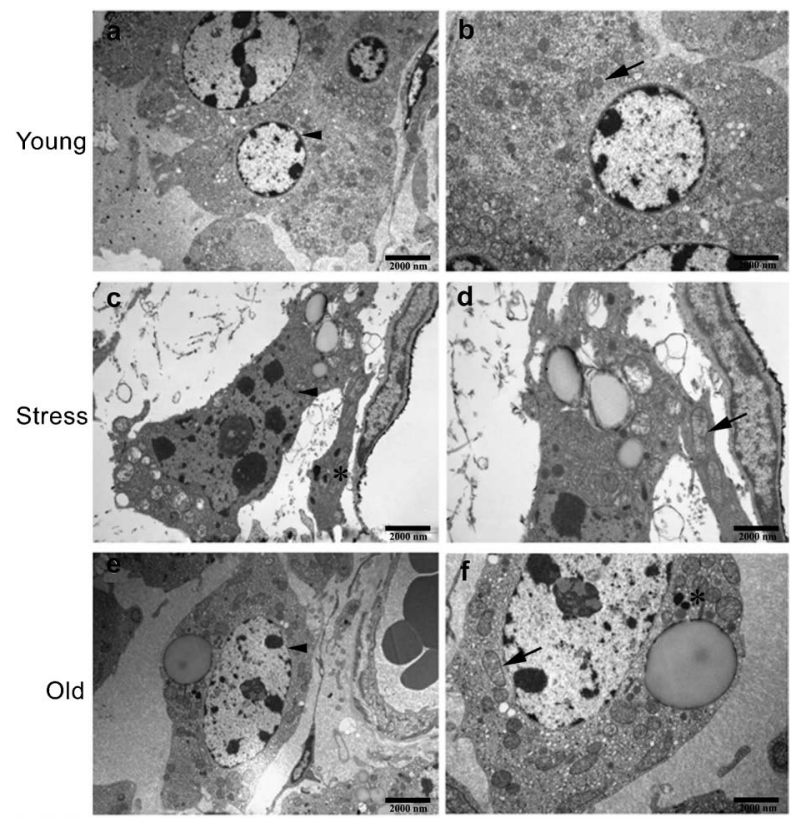

Figure 3 The ultrastructures of rat Leydig cells were observed using a transmission electron microscope (TEM). (a, b) Images of Leydig cells from young control rats (6-month-old). The Leydig cells were large and satiation and had a normal shape and structure, including abundant smooth endoplasmic reticulum and a prominent rim of heterochromatin beneath the nuclear membrane. (c, d) Images of Leydig cells from stressed rats. (e, f) Images of Leydig cells from old rats (21month-old). In contrast with Leydig cells from young control rats, aggregation of nuclear chromatin (black arrowhead), dilation of the endoplasmic reticulum, mitochondrial swelling (black arrow), large lipid droplets, nucleolus enlargement and increased lipofuscin accumulation (asterisk) were apparent in Leydig cells from both chronically stressed and aged rats. Scale bars $=2000 \mathrm{~nm}$.

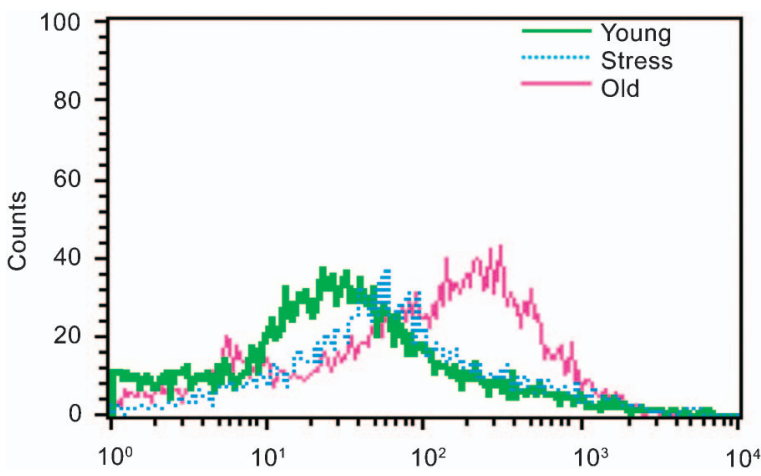

Figure 4 Lipofuscin deposition in rat Leydig cells was observed using flow cytometer. Leydig cells isolated from chronic stress rats displayed a prominent increase in cellular autofluorescence compared to cells from young control rats, approximately sixfold after 40 days of chronic stress. Leydig cells isolated from old rats displayed on average a $>10$-fold increase in autofluorescence comparison to Leydig cells from young control rats, consistent with senescence.

\section{Chronic stress augments ROS production in Leydig cells}

ROS have been reported to inhibit testicular steroidogenesis, and ROS production is known to promote senescence. ${ }^{6}$ We determined the concentrations of ROS in Leydig cells from chronically stressed rats by assessing relative DCFH intensity using flow cytometry. The results showed that chronic stress dramatically elevated Leydig cell ROS levels. Leydig cells isolated from old rats also displayed marked increases in intracellular ROS levels compared to Leydig cells from young control rats $(P<0.05)$ (Figure 5). Collectively, these results demonstrated that chronic stress augmented ROS production in Leydig cells to levels similar to ROS levels observed in the old rats.

\section{Chronic stress induces DNA damage in Leydig cells}

DNA damage can be found in senescent cells, and a certain degree of DNA damage contributes to premature senescence. ${ }^{18,28,29}$ The 'comet assay' has been used extensively as a sensitive measurement of DNA damage in cells. ${ }^{30,31}$ Therefore, we next performed the comet assay to detect any nuclear DNA lesions induced by chronic stress, especially in Leydig cells. As shown in Figure 6a and b, DNA damage in Leydig cells from rats in the chronic stress group was markedly apparent compared with that of cells taken from young control rats. We also observed intense DNA damage in Leydig cells from aged rats (Figure 6c).

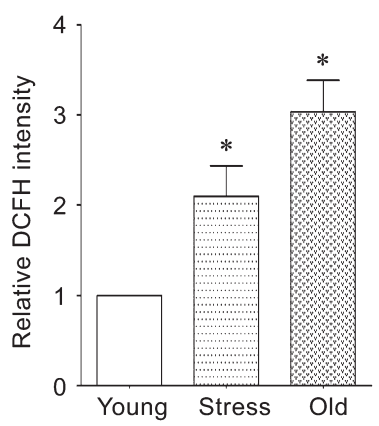

Figure 5 Reactive oxygen species (ROS) levels in Leydig cells were quantified using 2', 7'-dichlorodihydrofluorescein staining and flow cytometry. Cellular ROS levels, as reflected by relative DCFH intensity, were markedly elevated in Leydig cells isolated from the old rats. Chronic stress also significantly increased ROS production in Leydig cells from old rats compared to cells from young control rats. Each sample was run in duplicate, and the figure is representative of three assays. ${ }^{*} P<0.05$ compared with the Young group. 

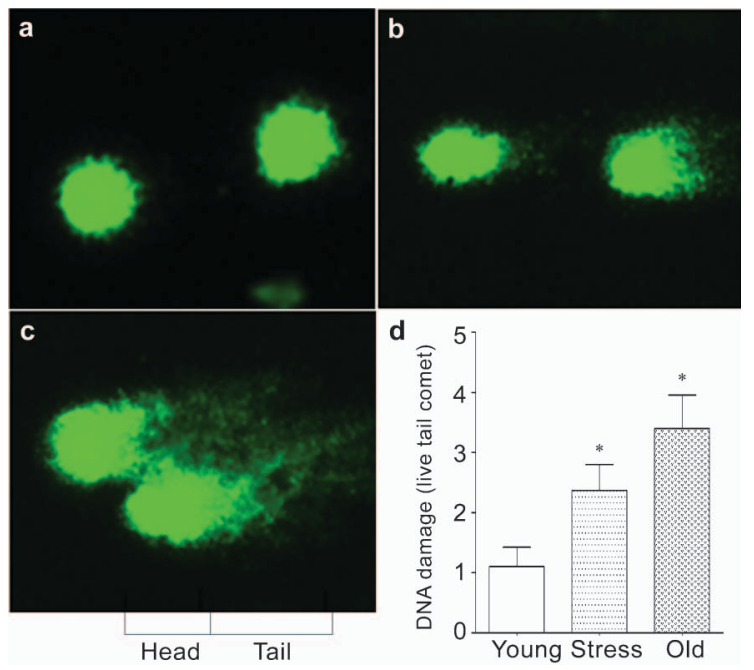

Figure 6 DNA damage in Leydig cells was observed using the comet assay. (a) Image of Leydig cell nucleoids using the comet assay; cells were isolated from 6month-old rats. The limited migration of DNA toward the anode indicates the cells have a low level of DNA damage. (b) Image of Leydig cell nucleoids; cells were isolated from rats exposed to chronic stress. The significant migration of DNA into the tail of the comet indicates greater DNA damage. (c) Image of Leydig cell nucleoids; cells were isolated from 21-month-old rats. DNA breaks within long loops of DNA allow them to migrate toward the anode, giving rise to a comet-like appearance in heavily damaged nucleoids. (d) DNA damage was measured using the comet assay and analysed using Comet 5.0 in Leydig cells of the three groups. *indicate a significant difference compared with the Young group $(P<0.05)$.

Together, these results indicated that chronic stress caused distinct DNA damage in Leydig cells (Figure 6d).

\section{DISCUSSION}

The ability of lifestyle and environmental changes to influence reproductive health is an interesting and relevant field of research. Our previous study has indicated that stress could induce glucocorticoid-mediated apoptosis in rat Leydig cells. ${ }^{19}$ Many studies have demonstrated that apoptosis may occur during ageing in various cell populations, including central nervous system cells, cardiomyocytes, hepatocytes and lymphocytes; further, ageing has been shown to sensitize cells to apoptotic stimuli. ${ }^{32}$ In our study, apoptotic Leydig cells in the reproductive system were observed in the young rats after exposure to chronic stress and ageing rats (Supplementary Figure 2). Furthermore, stress-induced ageing has been intensively studied in several organs. ${ }^{32,33}$ These findings prompted us to investigate whether prolonged chronic stress could also promote Leydig cell ageing.

The results reported here are the first to demonstrate that chronic stress accelerates degenerative changes in Leydig cells that are associated with ageing in $\mathrm{BN}$ rats. $\mathrm{BN}$ rats have become a well-accepted model for human reproductive ageing. Previous studies have demonstrated that $\mathrm{BN}$ rats do not develop reproductive tract tumours, gain little weight and are long-lived, characteristics that make it possible to clearly study age-associated changes. ${ }^{34,35}$ After being subjected to prolonged and repeated stress, Leydig cells from adult rats develop an adaptive response, characterized by the upregulation of PKA and StAR protein expression. ${ }^{36}$ To avoid this adaptation, we successfully established a model of chronic unpredictable stress.

Here, we reported that after exposure to chronic unpredictable stress for 40 days, male BN rats (6-month-old) displayed decreased serum testosterone levels; reduced testis weights; and dramatic degenerative changes in the Leydig cells that included highly condensed chromatin, mitochondrial swelling and lipofuscin deposition. Because no remarkable changes in Leydig cell counts were observed, these data suggest that the reduced steroidogenic capability in these rats must result from the decreased ability of individual Leydig cell to produce testosterone. Taken together, these findings exhibit an ageassociated phenotype, indicating that chronic stress could induce premature senescence in Leydig cells.

To further test our hypothesis, we also examined other cellular markers of senescence such as SA- $\beta$ gal activity. ${ }^{37,38}$ In the present study, Leydig cells from either the young control or the stressed rats stained blue after $5 \mathrm{~h}$ of SA- $\beta$ gal staining; similar results were obtained with the aged Leydig cells (data not shown). Therefore, SA- $\beta$ gal staining was not an appropriate method to distinguish between young and senescent Leydig cells. In our report, increased cellular lipofuscin deposition was observed in Leydig cells from the aged BN rats using ultrastructural analysis. For the first time, we used cellular autofluorescence to detect the quantity of lipofuscin in Leydig cells. High levels of lipofuscin, which is a widely used marker of cellular senescence, were observed in Leydig cells from BN rats exposed to unpredictable stress conditions for 40 days.

Ageing and cellular senescence are complicated processes that involve numerous causes and consequences. ${ }^{39}$ Basic biological processes that cause ageing include changes in gene expression, ${ }^{40}$ the metabolic generation of chemical radicals, ${ }^{12}$ failed DNA repair ${ }^{28}$ and telomere shortening. ${ }^{40}$ Among these, the metabolic generation of free radicals is most consistent with the studies of Leydig cells owing to the large number of electron transfer reactions that take place in Leydig cells. Ageing mechanisms based on DNA replication, including replication error and telomere shortening, do not readily apply to Leydig cell senescence because Leydig cells are post-replicative. ${ }^{41}$

Leydig cells endogenously produce ROS from several sources, including the mitochondrial electron transport chain and microsomal cytochrome P450 enzymes. ${ }^{42,43}$ Additionally, cyclooxygenase and lipoxygenase enzymes, which are expressed in Leydig cells, have been demonstrated to be significant sources of $\operatorname{ROS}^{44}$ and appear to be critically involved in steroid synthesis. ${ }^{45}$ In fact, long-term suppression of steroidogenesis through the administration of contraceptive doses of testosterone can prevent or delay age-related degeneration in rats in vivo. ${ }^{46}$ Additionally, low-dose testosterone treatment can decrease ROS production and subsequent oxidative damage in Leydig cells in vitro. ${ }^{47}$ ROS generated both from normal metabolism and in the process of steroidogenesis in Leydig cells, followed by ageassociated degeneration and testicular steroidogenesis inhibition. Consistent with previous reports, we showed that ROS levels were increased in Leydig cells from aged rats. ${ }^{13}$ Although ROS are considered cytotoxic, they have also been recognized as important signalling molecules. Lee et $a l^{48}$ showed that ROS signalling-mediated c-Jun upregulation suppressed the expression of steroidogenic enzyme genes by inhibiting Nur77 transactivation, resulting in the reduction of testicular steroidogenesis. These findings may provide a mechanistic explanation for the observed age-related decline in testicular steroid hormone production.

Chronic stress-induced increases in ROS production in Leydig cells and subsequently increased DNA damage were proposed as the mechanisms through which stress or glucocorticoids increase the vulnerability of different testis regions, particularly Leydig cells. In addition to glucocorticoid, hormones also can induce DNA damage through the generation of single-strand breaks at physiological 
levels. ${ }^{49}$ Consistent with the hypothesis that the fate of the Leydig cells obtained from BN rats exposed to chronic stress is dependent on the magnitude of the ROS production and DNA damage, we proposed that sublethal but critical levels of ROS and DNA damage would rapidly promote premature senescence.

In summary, we showed that chronic stress could stimulate an increased production of ROS in Leydig cells. Thus, stress may add to the oxidant burden and its consequent damage to DNA appears to be a major contributor to cell senescence and ageing. It is plausible that increases in chronic stress-induced ROS and DNA damage play important roles in accelerating ageing-associated degenerative changes in Leydig cells.

\section{AUTHOR CONTRIBUTIONS}

PZ and HBG were responsible for the project application, the experiment design and the manuscript revision. FFW designed the experiments, carried out the study, analysed the data and wrote the manuscript. QW, YC and QL were involved in the animal experiments.

\section{COMPETING FINANCIAL INTERESTS}

The authors declare no competing financial interests.

\section{ACKNOWLEDGMENTS}

This work was supported by the NIH Foundation (No. R03TW007609-01). Animal feeding by Mr Liang Hu, from the Department of Biochemistry and Molecular Biology at Shanghai Jiao Tong University School of Medicine, is greatly appreciated.

Supplementary Information accompanies the paper on Asian Journal of Andrology's website (http://www.nature.com/aja).

1 Pare WP. The effect of chronic environmental stress on premature aging in the rat. J Gerontol 1965; 20: 78-84.

2 Landfield PW, Eldridge JC. Evolving aspects of the glucocorticoid hypothesis of brain aging: hormonal modulation of neuronal calcium homeostasis. Neurobiol Aging 1994; 15: 579-88.

3 Sapolsky RM. The physiological relevance of glucocorticoid endangerment of the hippocampus. Ann NY Acad Sci 1994;13: 294-304; discussion 304-7.

4 Reagan LP, McEwen BS. Controversies surrounding glucocorticoid-mediated cell death in the hippocampus. J Chem Neuroanat 1997; 13: 149-67.

5 Maric D, Kostic T, Kovacevic R. Effects of acute and chronic immobilization stress on rat Leydig cell steroidogenesis. J Steroid Biochem Mol Biol 1996; 58: 351-5.

6 Harman SM, Metter EJ, Tobin JD, Pearson J, Blackman MR. Longitudinal effects of aging on serum total and free testosterone levels in healthy men. Baltimore Longitudinal Study of Aging. J Clin Endocrinol Metab 2001; 86: 724-31.

7 Matsumoto AM. Andropause: clinical implications of the decline in serum testosterone levels with aging in men. J Gerontol A Biol Sci Med Sci 2002; 57: M76-99.

8 Vermeulen A. Clinical review 24: androgens in the aging male. J Clin Endocrinol Metab 1991; 73: 221-4.

9 Hardy MP, Gao HB, Dong Q, Ge R, Wang Q et al. Stress hormone and male reproductive function. Cell Tissue Res 2005; 322: 147-53.

10 Brunk UT, Terman A. The mitochondrial-lysosomal axis theory of aging: accumulation of damaged mitochondria as a result of imperfect autophagocytosis. Eur J Biochem 2002; 269: 1996-2002.

11 Ruffoli R, Carpi A, Giambelluca MA, Grasso L, Scavuzzo MC et al. Diazepam administration prevents testosterone decrease and lipofuscin accumulation in testis of mouse exposed to chronic noise stress. Andrologia 2006; 38: 159-65.

12 Beckman KB, Ames BN. The free radical theory of aging matures. Physiol Rev 1998; 78: 547-81.

13 Chen $\mathrm{H}$, Cangello D, Benson S, Folmer J, Zhu H et al. Age-related increase in mitochondrial superoxide generation in the testosterone-producing cells of Brown Norway rat testes: relationship to reduced steroidogenic function? Exp Gerontol 2001; 36: 1361-73.

14 Cao L, Leers-Sucheta S, Azhar S. Aging alters the functional expression of enzymatic and non-enzymatic anti-oxidant defense systems in testicular rat Leydig cells. J Steroid Biochem Mol Biol 2004; 88: 61-7.

15 Garinis GA, van der Horst GT, Vijg J, Hoeijmakers JH. DNA damage and ageing: newage ideas for an age-old problem. Nat Cell Biol 2008; 10: 1241-7.

16 Chen JH, Hales CN, Ozanne SE. DNA damage, cellular senescence and organismal ageing: causal or correlative? Nucleic Acids Res 2007; 35: 7417-28.
17 Bertram C, Hass R. Cellular responses to reactive oxygen species-induced DNA damage and aging. Biol Chem 2008; 389: 211-20.

18 Seviour EG, Lin SY.The DNA damage response: balancing the scale between cancer and ageing. Aging (Albany NY) 2010; 2: 900-7.

19 Chen Y, Wang Q, Wang FF, Gao HB, Zhang P. Stress induces glucocorticoid-mediated apoptosis of rat Leydig cells in vivo. Stress 2012; 15: 74-84.

20 Gundersen HJ. Stereology of arbitrary particles. A review of unbiased number and size estimators and the presentation of some new ones, in memory of William R. Thompson. J Microsc 1986; 143: 3-45.

21 Wang C, Leung A, Sinha-Hikim AP. Reproductive aging in the male brown-Norway rat: a model for the human. Endocrinology 1993; 133: 2773-81.

22 Papanicolaou KN, Ngoh GA, Dabkowski ER, O'Connell KA, Ribeiro RF et al. Cardiomyocyte deletion of mitofusin-1 leads to mitochondrial fragmentation and improves tolerance to ROS-induced mitochondrial dysfunction and cell death. Am J Physiol Heart Circ Physiol 2012; 302: H167-79.

23 Wang Q, Gao HB. Involvement of nuclear factor-kappa B on corticosterone-induced rat Leydig cell apoptosis. Asian J Androl 2006; 8: 693-702.

24 Payne AH, Downing JR, Wong KL. Luteinizing hormone receptors and testosterone synthesis in two distinct populations of Leydig cells. Endocrinology 1980; 106: 1424-9.

25 Mahfouz RZ, du Plessis SS, Aziz N, Sharma R, Sabanegh E et al. Sperm viability, apoptosis, and intracellular reactive oxygen species levels in human spermatozoa before and after induction of oxidative stress. Fertil Steril 2010; 93: 814-21.

26 Munck A, Guyre PM, Holbrook NJ. Physiological functions of glucocorticoids in stress and their relation to pharmacological actions. Endocr Rev 1984; 5: 25-44.

27 Yates KE, Korbel GA, Shtutman M, Roninson IB, DiMaio D. Repression of the SUMOspecific protease Senp1 induces p53-dependent premature senescence in normal human fibroblasts. Aging Cell 2008; 7: 609-21.

28 Lombard DB, Chua KF, Mostoslavsky R, Franco S, Gostissa M et al. DNA repair, genome stability, and aging. Cell 2005; 120: 497-512.

29 Gruz P, Shimizu M. Origins of age-related DNA damage and dietary strategies for its reduction. Rejuvenation Res 2010; 13: 285-7.

30 Herbert KE, Mistry Y, Hastings R, Poolman T, Niklason L et al. Angiotensin IImediated oxidative DNA damage accelerates cellular senescence in cultured human vascular smooth muscle cells via telomere-dependent and independent pathways. Circ Res 2008; 102: 201-8.

31 Inturi S, Tewari-Singh N, Gu M, Shrotriya S, Gomez J et al. Mechanisms of sulfur mustard analog 2-chloroethyl ethyl sulfide-induced DNA damage in skin epidermal cells and fibroblasts. Free Radic Biol Med 2011; 51: 2272-80.

32 Chen J, Patschan S, Goligorsky MS. Stress-induced premature senescence of endothelial cells. J Nephrol 2008; 21: 337-44.

33 Landfield PW, Eldridge JC. Evolving aspects of the glucocorticoid hypothesis of brain aging: hormonal modulation of neuronal calcium homeostasis. Neurobiol Aging 1994; 15: 579-88.

34 Zirkin BR, Santulli R, Strandberg JD, Wright WW, Ewing LL. Testicular steroidogenesis in the aging Brown Norway rat. J Androl 1993; 14: 118-23.

35 Chen H, Hardy MP, Huhtaniemi I, Zirkin BR. Age-related decreased Leydig cell testosterone production in the Brown Norway rat. J Androl 1994; 15: 551-7.

36 Kostic TS, Stojkov NJ, Janjic MM, Maric D, Andric SA. The adaptive response of adult rat Leydig cells to repeated immobilization stress: the role of protein kinase $A$ and steroidogenic acute regulatory protein. Stress 2008; 11: 370-80.

37 Dimri GP, Lee X, Basile G, Acosta M, Scott G et al. A biomarker that identifies senescent human cells in culture and in aging skin in vivo. Proc Natl Acad Sci USA 1995; 92: 9363-7.

38 Kang HT, Lee KB, Kim SY, Choi HR, Park SC. Autophagy impairment induces premature senescence in primary human fibroblasts. PLOS ONE 2011; 6: e23367.

39 McClearn GE. Biogerontologic theories. Exp Gerontol 1997; 32: 3-10.

40 Collado M, Blasco MA, Serrano M. Cellular senescence in cancer and aging. Cell 2007; 130:22333.

41 Russell LD, de Franca LR, Hess R, Cooke P. Characteristics of mitotic cells in developing and adult testes with observations on cell lineages. Tissue Cell 1995; 27: 105-28.

42 Quinn PG, Payne AH. Oxygen-mediated damage of microsomal cytochrome P-450 enzymes in cultured Leydig cells. Role in steroidogenic desensitization. J Biol Chem 1984; 259: 4130-5.

43 Hanukoglu I. Antioxidant protective mechanisms against reactive oxygen species (ROS) generated by mitochondrial P450 systems in steroidogenic cells. Drug Metab Rev 2006; 38: 171-96

44 Spiteller G. Lipid peroxidation in aging and age-dependent diseases. Exp Gerontol 2001; 36: 1425-57.

45 Wang XJ, Dyson MT, Jo Y, Eubank DW, Stocco DM. Involvement of 5-lipoxygenase metabolites of arachidonic acid in cyclic AMP-stimulated steroidogenesis and steroidogenic acute regulatory protein gene expression. J Steroid Biochem Mol Biol 2003; 85: 159-66.

46 Chen $\mathrm{H}$, Zirkin BR. Long-term suppression of Leydig cell steroidogenesis prevents Leydig cell aging. Proc Natl Acad Sci USA 1999; 96: 14877-81.

47 Hwang TI, Liao TL, Lin JF, Lin YC, Lee SY et al. Low-dose testosterone treatment decreases oxidative damage in TM3 Leydig cells. Asian J Androl $2011 ; 13: 432-7$.

48 Lee SY, Gong EY, Hong CY, Kim KH, Han JS et al. ROS inhibit the expression of testicular steroidogenic enzyme genes via the suppression of Nur77 transactivation. Free Radic Biol Med 2009; 47: 1591-600.

49 Yared E, McMillan TJ, Martin FL. Genotoxic effects of oestrogens in breast cells detected by the micronucleus assay and the Comet assay. Mutagenesis 2002; 17: 345-52. 